\title{
Cyclic AMP, Trehalase and Germination of Phycomyces blakesleeanus Spores
}

\author{
By RAYMOND M. VAN MULDERS AND ANDRE J. VAN LAERE* \\ Laboratory for Plant Biochemistry, Katholieke Universiteit Leuven, Kardinaal Mercierlaan 92, \\ B-3030 Heverlee, Belgium
}

(Received 27 October 1983)

\begin{abstract}
When heat activated Phycomyces blakesleeanus spores were incubated at room temperature a rapid and transient increase in cyclic AMP content was observed. A similar increase was observed during the heat treatment itself but the cyclic AMP content had returned to the value of dormant spores at the end of the 5 min treatment. The cyclic AMP content increased only after treatments at temperatures which also induced spore germination. A more gradual rise in cyclic AMP was also found during activation at room temperature with acetate and after activation of the spores with pyrosulphite. The increase in cyclic AMP content is the earliest event known to occur after activation of the spores. It clearly preceded the increase in trehalase activity observed during and/or after all the activating treatments, suggesting that, as shown for in vitro activation, the in vivo activation of trehalase is due to a cyclic AMP-dependent phosphorylation. An increase in cyclic AMP was a common feature of all activation methods investigated and appears to be the factor triggering spore germination.
\end{abstract}

\section{INTRODUCTION}

The sporangiospores of Phycomyces blakesleeanus do not germinate under conditions suitable for growth and development of the organism, but require activation by physical or chemical means. Heating for some minutes at about $50{ }^{\circ} \mathrm{C}$ (Robbins et al., 1942) or addition of acetate (Borchert, 1962) will result in nearly $100 \%$ germination. Germination of the spores is accompanied by a decrease in trehalose content (Rudolph \& Ochsen, 1969), the main reserve substance of dormant spores (up to $30 \%$ of the spore dry weight). This decrease coincides with a more than tenfold increase in trehalase activity observed after activation by either heat (Van Assche et al., 1972) or acetate (Delvaux, 1973). It was suggested that this trehalose breakdown was responsible for the induction of the initial steps of germination and thus for the irreversibility of the activated state (Van Laere et al., 1980a). Shortly after activation the concentration of hexose monophosphates and bisphosphates increases sharply (Van Laere et al., 1983) and respiration and fermentation increase dramatically. Although some treatments activate the spores without a simultaneous increase in trehalase activity (Van Assche et al., 1977, 1978; Van Laere $e t a l ., 1980 b$; Thevelein $e t$ al., 1980), this activity increases rapidly during subsequent incubation in a glucose-containing medium (Thevelein et al., 1983). Recently it has been shown that trehalase from dormant spores can be activated in vitro by a cyclic AMP- and ATPdependent process, suggesting a phosphorylation of the enzyme (Van Laere \& Hendrix, 1983). If such a mechanism also occurs in vivo one could expect a change in the concentration of cyclic AMP during or after the activating treatments. Such a change could also affect the degree of phosphorylation of other enzymes. Here we report the occurrence of such changes in cyclic AMP concentration and their relation with trehalase activation and spore germination. 


\section{METHODS}

Organism. Strain $\mathrm{K}^{+}$of Phycomyces blakesleeanus Burgeff, from the collection of W. Halbsguth, was cultured on sterile moistened brown bread in the dark at $18^{\circ} \mathrm{C}$ and $70 \%$ relative humidity. Spores were grown, harvested, dried and stored as described previously (Van Assche et al., 1972).

Activation of the spores. Spores $\left(10 \mathrm{mg} \mathrm{ml}^{-1}\right)$ were preincubated in $10 \mathrm{mM}-\mathrm{KH}_{2} \mathrm{PO}_{4}$ at $\mathrm{pH} 6.5$ with or without $1.5 \%(w / v)$ glucose for $30 \mathrm{~min}$ at $25^{\circ} \mathrm{C}$. Heat activation was done by shaking this spore suspension in a water bath for $5 \mathrm{~min}$ at $38,42,46$ or $50^{\circ} \mathrm{C}$. After the heat shock the suspension was immediately cooled in an ice bath and further incubated at $25^{\circ} \mathrm{C}$. For acetate activation, spores $\left(10 \mathrm{mg} \mathrm{ml}^{-1}\right)$ were presoaked in water for $30 \mathrm{~min}$ at $25{ }^{\circ} \mathrm{C}$, collected by centrifugation and resuspended in a medium containing $0.1 \mathrm{M}$-acetic acid and $0.01 \mathrm{M}-\mathrm{H}_{3} \mathrm{PO}_{4}$ brought to pH 6.5 with ammonia. Activation by pyrosulphite was done by shaking a spore suspension $\left(10 \mathrm{mg} \mathrm{ml}^{-1}\right)$ in $0.1^{\circ} \mathrm{o}(\mathrm{w} / \mathrm{v}) \mathrm{Na}_{2} \mathrm{~S}_{2} \mathrm{O}_{5}$ for $15 \mathrm{~min}$ in a water bath at $25^{\circ} \mathrm{C}$. The spores were then collected by centrifugation, washed twice with distilled water and resuspended $\left(10 \mathrm{mg} \mathrm{ml}^{-1}\right)$ in $10 \mathrm{mM}-\mathrm{KH}_{2} \mathrm{PO}_{4}$ with $1.5 \%$ (wiv) glucose pH 6.5.

Determination of the cyclic AMP content. At the appropriate stages of development spore suspension ( $2 \mathrm{ml}$, containing $20 \mathrm{mg}$ spores) was rapidly filtered on Whatman glass fibre filters (GF/C, $25 \mathrm{~mm}$ ). Within $5 \mathrm{~s}$ from the time the spores were removed from the culture flasks, the filters were immersed in liquid $\mathrm{N}_{2}$. The frozen spores were homogenized in a Teflon container with $0.8 \mathrm{ml}$ glass beads of $3 \mathrm{~mm}$ diameter and $2.2 \mathrm{ml}$ glass beads of $1 \mathrm{~mm}$ diameter. Both container and glass beads were precooled in liquid $\mathrm{N}_{2}$. After 3 min vibration at an amplitude of $10 \mathrm{~mm}$ (Braun microdismembrator), and before the contents of the container were thawed, $1 \mathrm{ml}$ of a solution containing $1 \mathrm{M}-\mathrm{HClO}_{4}$ and $5 \mathrm{mM}$-EDTA was added to the frozen powder of dry spores. Vibration was continued for some $3 \mathrm{~min}$ at the same amplitude until the contents were thawed. The homogenate was centrifuged for $2 \mathrm{~min}$ at $10000 \mathrm{~g}$. A $0.5 \mathrm{ml}$ sample of the supernatant was neutralized by adding $50 \mu \mathrm{l} 5 \mathrm{M}-\mathrm{K}_{2} \mathrm{CO}_{3}$ and $50 \mu \mathrm{l} 2 \mathrm{M}-\mathrm{Tris} / \mathrm{HCl}$ buffer $\mathrm{pH} 7.5$. The potassium perchlorate was precipitated by centrifugation for $2 \mathrm{~min}$ at $1000 \mathrm{~g}$. A $50 \mu \mathrm{l}$ sample of the supernatant was used for cyclic AMP determination, which was done according to Tovey et al. (1974), with an assay kit (Amersham). In control experiments, samples treated with phosphodiesterase (Boehringer-Mannheim) before the cyclic AMP assay yielded zero values. Addition of a known amount of cyclic AMP to some extracts yielded recoveries near $100 \%$

Trehalase assay and protein determination. For the determination of trehalase specific activity spore suspension $(0.5 \mathrm{ml}$, containing $5 \mathrm{mg}$ spores) was rapidly injected into $1 \mathrm{ml}$ distilled water and centrifuged for about $10 \mathrm{~s}$ at $10000 \mathrm{~g}$. When glucose was present in the medium, the spores were resuspended in distilled water and centrifuged for another $10 \mathrm{~s}$. The spores were then quickly suspended in $0.5 \mathrm{ml}$ ice-cold $10 \mathrm{~mm}$-potassium phosphate buffer pH 6.5 containing $10 \mathrm{~mm}-\mathrm{NaF}$ and $1 \mathrm{~mm}$-phenylmethylsulphonyl fluoride, and homogenized by vortexing with $1.2 \mathrm{ml}$ glass beads of $0.5 \mathrm{~mm}$ diameter in a test tube of $11 \mathrm{~mm}$ diameter for $1 \mathrm{~min}$. A sample of the $2 \mathrm{~min}, 10000 \mathrm{~g}$ supernatant was assayed for trehalase specific activity as described previously (Thevelein et al., 1983). Protein content was determined by the Lowry method. Since trehalase activity changed very quickly after heat activation we tried to minimize time delays in some experiments: a $1.0 \mathrm{ml}$ sample (containing $10 \mathrm{mg}$ spores) was filtered onto a Whatman glass fibre filter (GF/C, $25 \mathrm{~mm}$ ) and submerged in liquid $\mathrm{N}_{2}$ within $5 \mathrm{~s}$. The filters were treated as for the cyclic AMP determinations except that the extraction was done in the potassium phosphate buffer described above. Since, for unknown reasons, this method yielded a much lower activity it was only used in some experiments to verify the time course of changes in trehalase activity.

Determination of percentage germination. Spore suspensions $(0.2 \mathrm{ml}$, containing $2 \mathrm{mg}$ spores) were centrifuged, washed with distilled water and resuspended in $1 \mathrm{ml}$ minimal nutrient medium (Rudolph, 1958). Percentage germination was determined under a microscope after incubation for 6 to $8 \mathrm{~h}$ at $25^{\circ} \mathrm{C}$. Usually, a total of 200 to 300 spores was counted.

\section{RESULTS}

Immediately after a 5 min heat treatment (at different temperatures) the concentration of cyclic AMP was not significantly different from that in dormant spores (Fig. 1). However, the concentration of cyclic AMP increased sharply during a subsequent incubation at $25^{\circ} \mathrm{C}$, reached a maximum after $2 \mathrm{~min}$ and then decreased to the level found in dormant spores. The cyclic AMP content increased only when the temperature of the heat shock was high enough to induce activation of the spores. Treatment at $38^{\circ} \mathrm{C}$ had no effect; after treatments at higher temperatures, the magnitude of the increase was dependent on the temperature of the heat shock. After a largely reversible activation at $42^{\circ} \mathrm{C}$, the presence of glucose in the medium prevented the spores from returning to the dormant state. The cyclic AMP concentrations measured 1,2 and 4 min after a heat treatment at $42^{\circ} \mathrm{C}$ were significantly larger $(P \leqslant 0.025)$ in the presence of glucose than in its absence. Even after irreversible activation of the spores (e.g. 


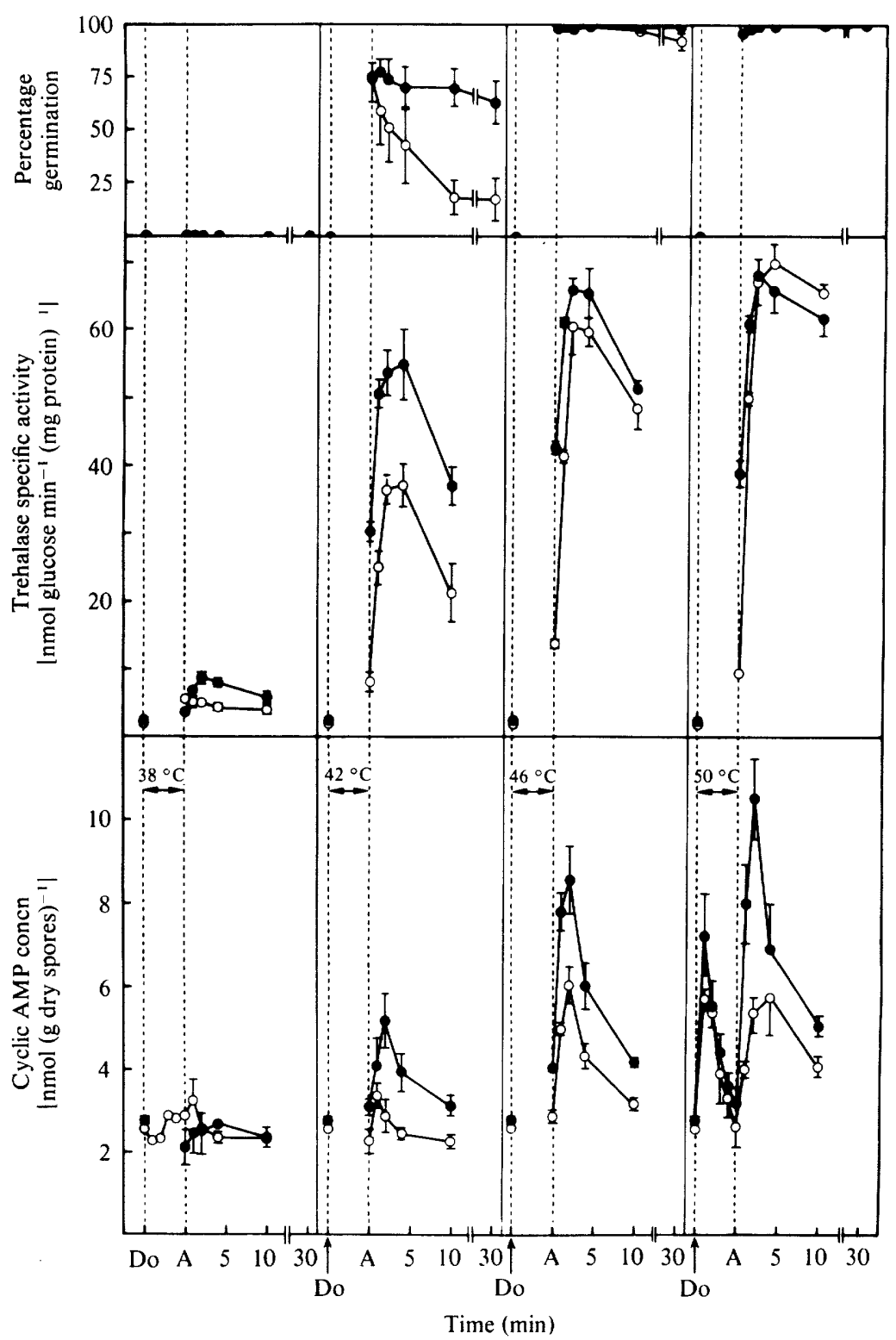

Fig. 1. Changes in cyclic AMP concentration, specific activity of trehalase and percentage germination during and after 5 min heat shocks at different temperatures in the absence $(O)$ or presence $(O)$ of exogenous glucose. The bars represent standard errors $(n=3)$. Do, start of heat treatment; $A$, end of heat treatment.

at 46 or $50^{\circ} \mathrm{C}$ ) the observed cyclic AMP contents were generally significantly larger when glucose was present in the medium. The highest increase (about fourfold) was obtained $2 \mathrm{~min}$ after a heat treatment at $50^{\circ} \mathrm{C}$ in a glucose-containing medium.

Cyclic AMP concentrations were also measured during a heat shock at $50^{\circ} \mathrm{C}$. Here, too, a large increase in cyclic AMP concentration was observed 1 min after the beginning of the heat treatment. During the following $4 \mathrm{~min}$, however, the cyclic AMP concentration decreased again to the level found in dormant spores. No increase in cyclic AMP content was observed during a heat treatment at $38^{\circ} \mathrm{C}$ (Fig. 1). 


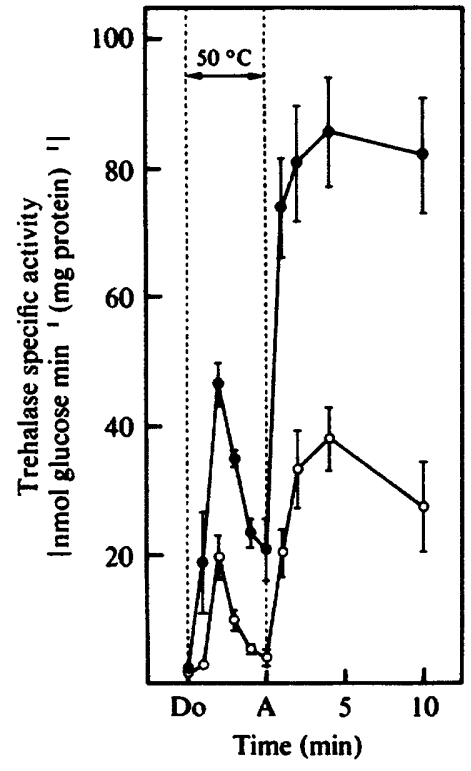

Fig. 2

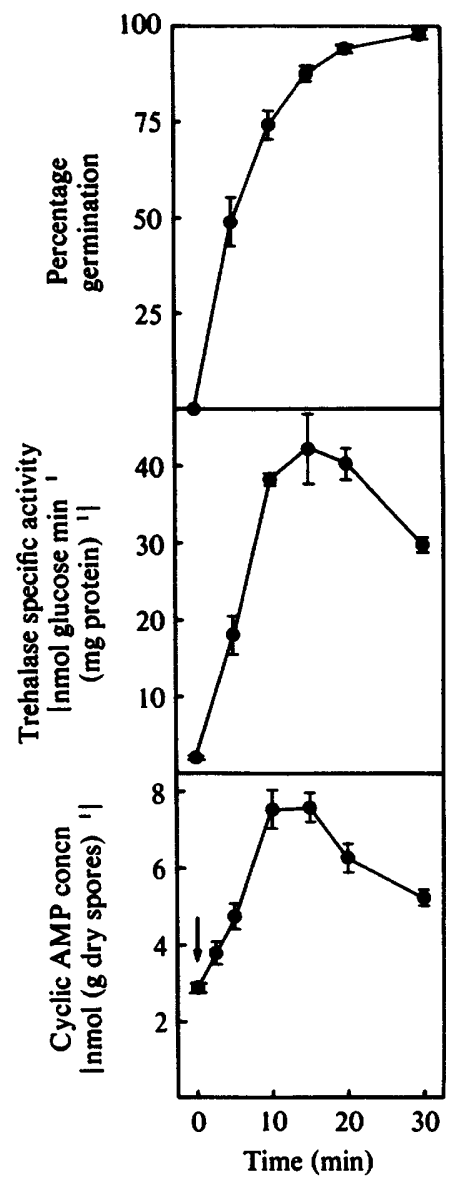

Fig. 3

Fig. 2. Specific activity of trehalase during and after a 5 min heat shock at $50^{\circ} \mathrm{C}$ in a medium without glucose as measured after two different sampling and homogenization methods. In the first method (O) the spores were centrifuged, washed and homogenized in buffer; about $40 \mathrm{~s}$ elapsed before homogenization. In the second method $(O)$ the spores were collected by filtration on glass fibre filters, quickly immersed in liquid $\mathrm{N}_{2}$ (after about $5 \mathrm{~s}$ ) and homogenized dry and frozen before addition of the buffer (see Methods). The bars represent standard errors $(n=3)$. Do, start of heat treatment; A, end of heat treatment.

Fig. 3. Changes in cyclic AMP concentration, specific activity of trehalase and percentage germination after addition of $0.1 \mathrm{M}$-ammonium acetate (indicated by the arrow) to dormant $P$. blakesleeanus spores. The bars represent standard errors $(n=3)$.

Only heat treatments which induced activation of the spores were followed by an increase in trehalase activity during subsequent incubation at $25^{\circ} \mathrm{C}$ (Fig. 1). Immediately after the heat shock, the specific activity of trehalase was already higher than in dormant spores, particularly in the presence of exogenous glucose. When glucose was present in the medium, however, the spores were given an extra washing before homogenization in order to avoid high blanks in the trehalase assay. This time period may have been sufficient to allow some increase in trehalase activity. In any case, the specific activity of trehalase further increased to reach a maximum after about $4 \mathrm{~min}$, thus following the maximum in cyclic AMP concentration (see also Fig. 2). Exogenous glucose enhanced the specific activity of trehalase after a heat treatment which caused a largely reversible activation of the spores. Indeed, the trehalase activities measured 1, 2 


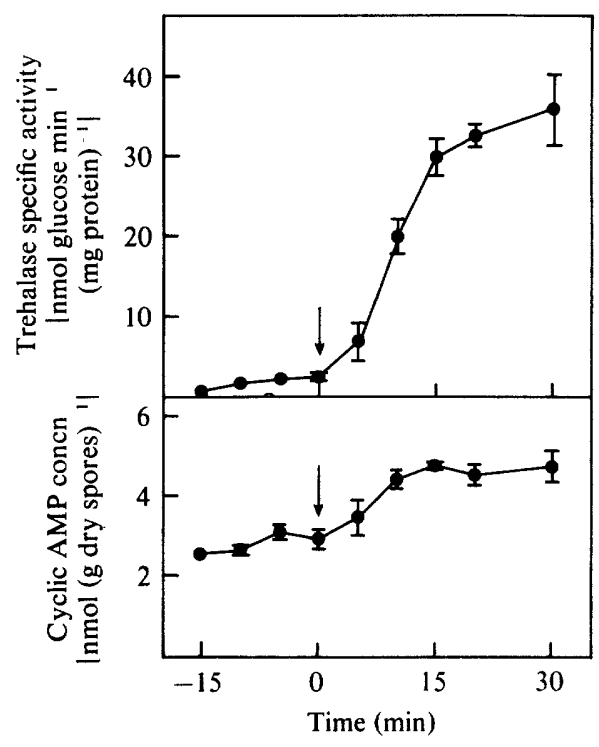

Fig. 4. Changes in cyclic AMP concentration and specific activity of trehalase during and after a 15 min treatment with pyrosulphite. The end of the pyrosulphite treatment is indicated by the arrows. The activating treatments yielded variable germination percentages $(67 \cdot 1 \% \pm 11 \cdot 2)$. The bars represent standard errors $(n=3)$.

and 4 min after a heat treatment at $42{ }^{\circ} \mathrm{C}$ were significantly larger $(P \leqslant 0.025)$ in the presence of glucose than in its absence. In contrast to its effect on cyclic AMP levels, exogenous glucose had no significant effect on the activity of trehalase after heat shocks at 46 and $50{ }^{\circ} \mathrm{C}$.

The specific activity of trehalase was also measured during a heat shock at $50^{\circ} \mathrm{C}$ (in the absence of glucose) (Fig. 2). Since we suspected that time delays before homogenization could allow activation of trehalase (e.g. as a result of cooling) a method was used that reduced the delay to less than $5 \mathrm{~s}$ (see Methods). Although this method apparently inactivated more than $50 \%$ of the trehalase, it showed that the activity of trehalase reached a maximum 2 min after the beginning of the heat treatment, paralleling the maximum in cyclic AMP concentration observed during the heat shock. The trehalase activity was again low at the end of the $5 \mathrm{~min}$ heat treatment.

The cyclic AMP concentration in the spores before and during incubation in $0.1 \mathrm{M}$ ammonium acetate is shown in Fig. 3. Addition of acetate induced a two- to threefold increase in cyclic AMP content as well as a sharp increase in trehalase activity during the 10 to 15 min period which was needed to activate the majority of the spores. The decrease in both cyclic AMP concentration and trehalase activity during further incubation was much slower than that after heat activation.

Treatment of $P$. blakesleeanus spores with $0 \cdot 1 \%(\mathrm{w} / \mathrm{v})$ sodium pyrosulphite activates them without a concomitant increase in trehalase activity (Van Assche et al., 1978). No significant increase in trehalase activity or in cyclic AMP concentration was observed during the incubation in pyrosulphite (Fig. 4). After the spores had been washed and incubated in a glucose-containing medium a twofold increase in cyclic AMP content and a concomitant increase in trehalase activity were observed. The fact that these effects were less pronounced than those observed for the other activation treatments could be due partly to the lower percentage germination induced by sodium pyrosulphite $(67 \cdot 1 \% \pm 11 \cdot 2)$.

\section{DISCUSSION}

The activation of trehalase has until now been the earliest event described during Phycomyces spore germination. However, we report here that the increase in trehalase activity after 
heat activation was preceded by a clearcut increase in cyclic AMP concentration. This increase in cyclic AMP concentration was observed only after heat treatments which induced activation of the spores. Surprisingly, a very rapid increase in cyclic AMP content was also found during the heat treatment itself. Treatment with $0.1 \mathrm{M}$-acetate caused a more gradual increase in both cyclic AMP and spore germination. Since a rise in cyclic AMP content was also found after pyrosulphite activation, the increase in cyclic AMP content appears to be a common feature of early germination in $\boldsymbol{P}$. blakesleeanus spores. During germination of Blastocladiella emersonii zoospores a maximum in cyclic AMP concentration was observed after 20 min germination (Vale et al., 1976), but during germination of Mucor spores the increase in cyclic AMP concentration was much slower and reached a maximum only after several hours (Paznokas \& Sypherd, 1975; Orlowski, 1980). During germination of Neurospora crassa conidia the endogenous levels of cyclic nucleotides did not change significantly (Rosenberg \& Pall, 1978).

Trehalase from dormant Phycomyces spores can be activated in vitro by a cyclic AMP- and ATP-dependent process (Van Laere \& Hendrix, 1983). Since the in vivo activation of trehalase was invariably preceded by an increase in cyclic AMP content, and since a decrease in cyclic AMP content was followed by a decrease in trehalase activity, a similar mechanism appears to operate in vivo. A parallel between cyclic AMP content and trehalase activity was observed during heat and acetate activation and after heat and pyrosulphite activation. Moreover, heat treatments at higher temperatures, resulting in higher cyclic AMP concentrations, were followed by higher trehalase activities (at least up to $46^{\circ} \mathrm{C}$, where saturation could occur). A similar mechanism for the in vivo activation of trehalase after glucose addition was inferred from results with vegetative yeast cells (Van der Plaat \& Van Solingen, 1974; Van Solingen \& Van der Plaat, 1975; Ortiz et al., 1983) and yeast ascospores (J. Thevelein, personal communication). An increase in cyclic AMP content and trehalase activity was also found after, but not during, a heat shock of yeast ascospores ( $\mathrm{J}$. Thevelein, personal communication).

Changes in cyclic AMP levels and in trehalase activity induced by $0.1 \mathrm{M}$-acetate were independent of the presence of exogenous glucose. However, trehalase activation after pyrosulphite activation of the spores is largely dependent on the presence of exogenous glucose (Thevelein et al., 1983). Exogenous glucose also prevented reversibly heat-activated spores from returning to the dormant state (Fig. 1; see also Van Laere et al., 1980a). The irreversibility of a heat treatment at $42^{\circ} \mathrm{C}$ in the presence of glucose was probably caused by the significantly higher cAMP content and/or the significantly higher trehalase activity in the presence of glucose than in its absence (Fig. 1). No such effect of glucose was found after a heat treatment at higher temperatures, where the amount of cyclic AMP could be saturating, even in the absence of glucose.

It has been proposed that plasma membrane depolarizations control cyclic AMP levels in fungi (Pall, 1977; Trevillyan \& Pall, 1979; Uno \& Ishikawa, 1981). Recently it has also been shown that addition of glucose and proton ionophores to yeast cells produced an immediate rise in cyclic AMP content and a concomitant inactivation of fructose-1,6-bisphosphatase (Mazon $e t$ $a l ., 1982 a, b)$. Addition of glucose and proton ionophores to yeast cells and to yeast ascospores also caused an immediate increase in trehalase activity ( $J$. Thevelein, personal communication). These phenomena have been explained by these authors by assuming a depolarization of the plasma membrane induced by glucose and the ionophores, although other authors believe that the effect of glucose on cyclic AMP levels in yeast is mediated by one of its catabolites (Purwin $e t$ $a l ., 1982)$. However, in contrast to the response in yeast, addition of glucose or proton ionophores to dormant $P$. blakesleeanus spores was not followed by an increase in cyclic AMP concentration nor in trehalase activity (not shown).

Despite its transience, the increase in cyclic AMP concentration could induce, via phosphorylation, dramatic increases in the activity not only of trehalase but also of other key regulatory enzymes. Since this increase is a common feature of different activation procedures, cyclic AMP might prove to be the signal controlling the relief of dormancy. 


\section{REFERENCES}

BorCherT, R. (1962). Über die Azetat-Aktivierung der Sporangiosporen von Phycomyces blakesleeanus. Beiträge zur Biologie der Pflanzen 38, 31-36.

Delvaux, E. (1973). Some aspects of germination induction in Phycomyces blakesleeanus by an ammonium acetate pretreatment. Archiv für Mikrobiologie 88, 273-284.

Mazon, M. J., Gancedo, J. M. \& Gancedo, C. $(1982 a)$. Inactivation of yeast fructose-1,6-bisphosphatase. Journal of Biological Chemistry 257, 11281130.

Mazon, M. J., Gancedo, J. M. \& Gancedo, C. $(1982 b)$. Phosphorylation and inactivation of yeast fructose-bisphosphatase in vivo by glucose and by proton ionophores. A possible role for cAMP. European Journal of Biochemistry 127, 605-608.

Orlowski, M. (1980). Cyclic adenosine 3',5'-monophosphate and germination of sporangiospores from the fungus Mucor. Archives of Microbiology 126, 133140.

Ortiz, C. H., Maia, J. C. C., Tenan, M. N., BrazPadrao, G. R., Mattoon, J. R. \& PaneK, A. D. (1983). Regulation of yeast trehalase by a monocyclic, cyclic AMP-dependent phosphorylationdephosphorylation cascade system. Journal of Bacteriology 153, 644-651.

PALL, M. L. (1977). Cyclic AMP and the plasma membrane potential in Neurospora crassa. Journal of Biological Chemistry 252, 7146-7150.

PAZnOKas, J. L. \& SyPHeRd, P. S. (1975). Respiratory capacity, cyclic adenosine 3',5'-monophosphate, and morphogenesis of Mucor racemosus. Journal of Bacteriology 124, 134-139.

Purwin, C., Leidig, F. \& Holzer, H. (1982). Cyclic AMP-dependent phosphorylation of fructose-1,6bisphosphatase in yeast. Biochemical and Biophysical Research Communications 107, 1482-1489.

Robbins, W. J., Kavanagh, V. W. \& Kavanagh, F. (1942). Growth substances and dormancy of spores of Phycomyces. Botanical Gazette 104, 224-242.

Rosenberg, G. \& Pall, M. L. (1978). Cyclic AMP and cyclic GMP in germinating conidia of Neurospora crassa. Archives of Microbiology 118, 87-90.

RuDOLPH, H. (1958). Entwicklungsphysiologische Untersuchungen an den Sporangiophoren von Phycomyces blakesleeanus. Biologisches Zentralblatt 77, 385-437.

RuDOLPH, H. \& OCHSEN, B. (1969). Trehalose-Umsatz wärmeaktivierter Sporen von Phycomyces blakesleeanus. Archiv für Mikrobiologie 65, 163-171.

Thevelein, J. M., Van Assche, J. A. \& Heremans, K. (1980). Effect of high pressure on the heat activation in vivo of trehalase in the spores of Phycomyces blakesleeanus. European Journal of Biochemistry 111, 171-175.

Thevelein, J. M., Van Laere, A. J., Beullens, M., VAN Assche, J. A. \& CARlier, A. R. (1983). Glucose-induced trehalase activation and trehalose mobilization during early germination of Phyco- myces blakesleeanus spores. Journal of General Microbiology 129, 719-726.

Tovey, K. C., Oldham, K. G. \& Whelan, J. A. M. (1974). A simple direct assay for cyclic AMP in plasma and other biological samples using an improved competitive protein binding technique. Clinica chimica acta 56, 221-234.

Trevillyan, J. M. \& Pall, M. L. (1979). Control of cyclic adenosine $3^{\prime}, 5^{\prime}$-monophosphate levels by depolarizing agents in fungi. Journal of Bacteriology 138, 397-403.

UNO, I. \& IsHIKaWA, T. (1981). Control of adenosine $3^{\prime}, 5^{\prime}$-monophosphate level and protein phosphorylation by depolarizing agents in Coprinus macrorhizus. Biochimica et biophysica acta 672, 108-113.

Vale, V. L., Gomes, S. L., Maia, J. C. C.\& MennucCI, L. (1976). Transient cyclic AMP accumulation in germinating zoospores of Blastocladiella emersonii. FEBS Letters 67, 189-192.

VAN Assche, J. A., CARLIER, A. R. \& DekeERsmaeker, H. I. (1972). Trehalase activity in dormant and activated spores of Phycomyces blakesleeanus. Planta 103, 327-333.

Van Assche, J. A., Carlier, A. R. \& Van Tieghem, L. L. C. (1977). The effect of gamma radiation on breaking of dormancy in Phycomyces spores. Archives of Microbiology 113, 95-97.

Van Assche, J. A., Van Laere, A. J. \& Carlier, A. R. (1978). Trehalose metabolism in dormant and activated spores of Phycomyces blakesleeanus Burgeff. Planta 139, 171-176.

VAN der PlaAt, J. B. \& Van Solingen, P. (1974). Cyclic 3',5'-adenosine monophosphate stimulates trehalose degradation in baker's yeast. Biochemical and Biophysical Research Communications 56, 580587.

Van Laere, A. J. \& Hendrix, P. (1983). Cyclic AMPdependent in vitro activation of trehalase from dormant Phycomyces blakesleeanus spores. Journal of General Microbiology 129, 3287-3290.

Van Laere, A. J., VAN Assche, J. A. \& Carlier, A. R. $(1980 a)$. Reversible and irreversible activation of Phycomyces blakesleeanus spores. Experimental Mycology 4, 96-104.

Van Laere, A. J., Van Assche, J. A. \& Carlier, A. R. $(1980 \mathrm{~b})$. Metabolism and chemical activation of Phycomyces blakesleeanus spores. Experimental Mycology 4, 260-268.

VAN LAere, A. J., Van Schaftingen, E. \& Hers, H.-G. (1983). Fructose 2,6-bisphosphate and germination of fungal spores. Proceedings of the National Academy of Sciences of the United States of America 80, 6601-6605.

Van Solingen, P. \& Van der PlaAt, J. B. (1975). Partial purification of the protein system controlling the breakdown of trehalose in baker's yeast. Biochemical and Biophysical Research Communications 62, 553-560. 